\title{
Structural Characteristics and Collagen Reaction Ability of Polyphenols in Larch Tanning Wastewater - an Important Hint for Vegetable Tanning Wastewater Recycling
}

\author{
Bo Teng ${ }^{1}$, Jiacheng Wu${ }^{1}$, Yao Wang ${ }^{1}$, Wuyong Chen ${ }^{1,2 *}$ \\ ${ }^{1}$ National Engineering Laboratory for Clean Technology of Leather Manufacture, Sichuan University, \\ 610065, Chengdu, China \\ ${ }^{2}$ Key Laboratory for Leather Chemistry and Engineering of the Education Ministry, Sichuan University, \\ 610065, Chengdu, China
}

Received: 22 January 2017

Accepted: 28 March 2017

\begin{abstract}
Wastewater recycling technologies have been widely used in tanneries to reduce environmental impacts. However, only a few recycling methods have been developed for vegetable tanning processes due to limited knowledge of their wastewaters. In this study, the structures of the polyphenols in the larch tanning wastewater (LTW) and commercial larch tannin (CLT) were characterized with spectrographic and chromatographic analysis. Structures of these polyphenols were illustrated accordingly; their collagen reaction abilities were then tested with thermal analysis and visualized with a molecular docking software. Results showed that polyphenols in LTW and CLT were all procyanidins. However, average molecular weight of the polyphenols in LTW was 1104Da, in contrast to an obviously higher value for the CLT sample (3334Da). Meanwhile, the LTW presented obvious lower reactivity in the collagen-polyphenol reaction, including lower thermal stabilities and docking energies, fewer hydrogen bonds, and lower interaction energies. These results provide a hint for vegetable tanning wastewater recycling: because of these structural differences, reactivity of the polyphenols in wastewater are lower than the ones in commercial tannins. Therefore, before the recycling processes, polyphenols must be chemically modified in accordance with these structural differences.
\end{abstract}

Keywords: leather processing, larch tannin, polyphenols, vegetable tanning wastewater, wastewater recycling

*e-mail: wuyong.chen@163.com 


\section{Introduction}

Leather manufacturing is a chemical process on a natural biological matrix. In this process, a huge quantity of water and inorganic and organic chemicals are used, thereby discharging solid and liquid wastes into the environment [1-3]. It is calculated that about $450 \mathrm{~kg}$ of solid waste as well as $50 \mathrm{~m}^{3}$ of wastewater are released for every $200 \mathrm{~kg}$ of leather produced [4]. The tannery wastewater is well known as a complex liquid that contains high levels of organic loading, dissolved and suspended solids, saline, and other specific pollutants [5-10]. The wastewater also causes a series long-term affects to both water and soil [11-13]. Meanwhile, these pollutants also inevitably affect the microorganisms, plants, and even animals in the surrounding areas [12-14].

A recycling system is well known as an effective and easy way to minimize tannery pollutant emissions [1517]. Compared with conventional methods, it provides a higher chemical absorption and a lower environmental impact. It also has the advantage of decreasing the cost of leather manufacture through reducing chemical and water consumption. Many recycling methods were thereby developed for such highly contaminative procedures as unhairing, liming, pickling, and chrome tanning [18-19].

To provide an effective recycling method for chrome-tanning wastewater, composition and structure characterization of the chrome complexes were sufficiently studied by Davis and Scroggie [20]. Their research indicated that the chrome complexes throughout the complete molecular weight and charge distribution range were bound to the hide without distinction. Furthermore, the distribution of complexes in the wastewater were similar to that in the tanning liquors. Based on these results, direct recycling was proposed for the chrome tanning wastewater and proved to be a highly effective method after years of practice [21-22].

As for another important tanning method, 350,000 to 400,000 tons of vegetable tannins were being used around the world for leather processing, while $15 \%$ was discharged as wastewater [23]. This exhibits a longterm negative environmental effect due to its toxicity for microorganisms [24-25].

Vegetable tannins are composed of polyphenols with molecular weight ranging from 500 to $3000 \mathrm{Da}$, their polydispersity is considered as the most important characters, including molecular weights, subunit contents, and chemical configurations, and these structural characteristics are diractly related with their properties. Previous studies already discovered that these characteristics were closely related to their proteinbinding abilities [26]. However, some important questions remain for vegetable tanning wastewater, such as: are there any structural differences between the polyphenols in tanning liquid and wasterwater? More importantly, why are polyphenols in the wastewaters were bound to the collagens but remain as residules? These theoretical problems must be resolved before developing recycling methods for vegetable tanning effluents.
The larch tannin is extracted from the bark of the larch tree (Larix gmelinii (Rupr.) Kuzen) and classified to the condensed type [27]. It is famous for the pine-like fragrance and wildly used in the pre-tanning, tanning, and post-tanning process. In this study, a common vegetable tanning process was performed with a commercial larch tannin (CLT) to produce larch tanning wastewater (LTW). Then the polyphenols in LTW and CLT samples were characterized with a series of techniques, including Fourier transform infrared spectrum (FT-IR), nuclear magnetic resonance $\left({ }^{13} \mathrm{C} \mathrm{NMR}\right)$, gel permeation chromatography (GPC), and an elemental analyzer. The differences between the samples were studied, including the flavan3-ol subunit constitutes, stereochemistry, category of polyphenol, molecular weights, and quantity of sulfonic acid group. Then the collagen reaction abilities were also tested with thermal dynamic analysis as well as computer modeling to investigate the reason for the surpluses of these polyphenols. The results will provide a valuable reference for both recycling and treatment of vegetable tanning wastewater.

\section{Materials and Methods}

\section{Sample Preparation}

The CLT was purchased from Yakeshi tannin extract factory (Inner Mongolia, China). Total solids, tannins, non-tannins, and insoluble solids were determined by SLTC official methods of analysis [28] and are shown in Table 1.

The chemicals used in the following procedure were based on the weight of the limed hide, and the experiment was carried out as follows in a stainless-steel drum. $25.0 \mathrm{~kg}$ limed cattle hide was first processed with a conventional deliming and a bating method. The hide $(\mathrm{pH}=4.0)$ was then washed in a $400 \%$ float for $2 \mathrm{hr}$ and pickled with $7 \%$ sodium chloride, $0.5 \%$ formic acid, and $1.2 \%$ sulfuric acid for $4 \mathrm{hr}$. The $\mathrm{pH}$ of the float was determined to be 2.3 . After this step, the hide was neutralized to $\mathrm{pH} 4.0$ with $6 \%$ sodium thiosulfate for $1 \mathrm{hr}$. The hide was then tanned with $30 \% \mathrm{CLT}$ for $48 \mathrm{~h}$ at $25^{\circ} \mathrm{C}$. After complete penetration, the hide continued soaking in the float for $12 \mathrm{hr}$. Then LTW was collected from the wastewater. The total phenolics content in the LTW was determined as $106 \mathrm{~g} / \mathrm{L}$ with the Prussian blue method. Meanwhile, the condensed tannin content was determined to be $72 \mathrm{~g} / \mathrm{L}$ with butanol/HCL assay [29-30].

Both the LTW and the CLT solutions $(32.26 \mathrm{~g} / \mathrm{L}$, referenced with the total solid content of the LTW) were filtered with a medium-speed filter paper, then dialyzed against distilled water to remove simple phenolics and salts. The glucoses were removed with gel permeation on Sephadex LH-20 (GE, American) with 50\% methanol, and then the polyphenols were obtained with $50 \%$ acetone. After the solvents were successively removed by evaporation and lyophilization, the LTW and the CLT samples were prepared. 
Table 1. Components of the CLT used in the research.

\begin{tabular}{|c|c|c|c|c|}
\hline & $\begin{array}{c}\text { Total solids } \\
(\%)\end{array}$ & $\begin{array}{c}\text { Tannins } \\
(\%)\end{array}$ & $\begin{array}{c}\text { Non-tannins } \\
(\%)\end{array}$ & $\begin{array}{c}\text { Insoluble } \\
\text { solids (\%) }\end{array}$ \\
\hline CLT & 88.02 & 58.03 & 40.72 & 1.25 \\
\hline
\end{tabular}

\section{FT-IR Spectroscopy}

The LTW and CLT samples (about $2 \mathrm{mg}$ ) were mixed with $\mathrm{KBr}(100 \mathrm{mg})$ and ground to a powder (2 $\mu \mathrm{m}$ diameter), and $60 \mathrm{mg}$ of the mixtures were pressed to form pellets. The spectra of the samples were obtained using a Nicolet iS10 FT-IR instrument (Thermo Scientific, America), with a wavenumber range of $500-4,000 \mathrm{~cm}^{-1}$ at a resolution of $4 \mathrm{~cm}^{-1}$.

\section{${ }^{13} \mathrm{C}$ NMR Analysis}

NMR spectra were obtained using an AV II-400MHz spectrometer (Bruker, Switzerland), operating at $297 \mathrm{~K}$. The solvent was acetone- $d_{6}$ and $\mathrm{D}_{2} \mathrm{O}$ mixture (acetone- $d_{6}$ : $\left.\mathrm{D}_{2} \mathrm{O}=90: 10, \mathrm{v}: \mathrm{v}\right)$

\section{GPC Analysis}

The LTW and the CLT samples were dissolved in dimethyl formamide (DMF) and subjected to GPC analysis. We used an HLC-8320 gel permeation chromatograph (TOSOH Corporation, Japan) equipped with a differential refraction detector as well as a combination of a TSK gel and a Super AWM-H column to measure molecular weight. DMF as a mobile phase was pumped into the column with flow rate of $0.6 \mathrm{ml} / \mathrm{min}$ at $25^{\circ} \mathrm{C}$. A series of polymethylmethacrylate was used as standard markers.

\section{Thermal Dynamic Analysis}

$1.0 \mathrm{~g}$ hide powder was soaked with $40 \mathrm{~mL}$ distilled water in a conical flask for $1 \mathrm{~h}$, then $4.0 \mathrm{~g}$ polyphenols were added and kept in a CHZ-82 shaker incubator (Jintan, China) at a rotation speed of $120 \mathrm{r} / \mathrm{min}\left(20^{\circ} \mathrm{C}\right)$ for $24 \mathrm{~h}$. After the solvents were removed by lyophilization, the tanned hide powders were prepared.

The thermal stability of the tanned hide powders was tested in a differential scanning colorimeter (DSC) instrument (PERKIN-ELmyer). $4 \mathrm{mg}$ of tanned hide powder were tested under a nitrogen atmosphere at a rate of $5^{\circ} \mathrm{C} / \mathrm{min}$, heating from 20 to $120^{\circ} \mathrm{C}$.

\section{Molecular Docking Studies}

Molecular docking and dynamic analyses were carried out using Discovery Studio 3.0 (DS, Accelrys, San Diego, USA). Precollagen were built to correspond to the native bovine type I collagens from the Research Collaboratory for Structural Bioinformatics Protein Data Bank (RCSB PDB) ( $\alpha_{1}$ and $\alpha_{3}$ chains, Swiss-Prot: P02453, from 529 to 573; $\alpha_{2}$ chain, Swiss-Prot: P02465, from 776 to 820 ), the proline (Pro) was replaced by hydroxyproline (Hyp) only if it was shown at $\mathrm{Y}$ of the Gly-X-Y repeated structure. Then a 45-mercollagen triple helix was constructed using the Gencollagen package in the Object Technology Framework (University of California, USA, www.cgl.ucsf. edu./cgi-bin/gencollagen.py). The triple helix was energy minimized through a 6,000-step steepest descent process followed by a 6,000 -step conjugate gradient process, then the structure of the precollagen was obtained and defined as a receptor. In accordance with the results obtained from structure analysis, 3-mer and 11-mer polyflavonids were built to represent the LTW and CLT samples. Then the polyphenols were energy-minimized with MM2 method and defined as ligands. Docking processes were carried out with the CDOCKER protocol under the CHARMm forcefield. The grid extension was set to $30 \AA$. The best among the 10 ligand binding poses in each binding site were chosen for binding energy calculation; the docking poses with highest CDOCKER Interaction Energy were subjected to hydrogen bond analysis.

\section{Molecular Dynamic (MD) Analysis}

The complexes with highest binding energy were subjected to MD simulation. The peptide fragments outside the sphere were cut and telopeptides were restrained. Afterward, the simulation was performed with a Standard Dynamics Cascade module in the DS with CHARMm forcefield. A $7 \AA$ salvation shell was created around the complex, then the energy minimization was carried out with the atoms of protein and ligands restrained. According to the study presented by Chen, the SHAKE algorithm was applied to fix all bonds involving hydrogen atoms throughout the MD simulation [31]. The minimization was performed using both steepest descent and conjugante gradient with a maximum of up to 6,000 steps. Afterward, the complex was gradually heated from $50 \mathrm{~K}$ to $300 \mathrm{~K}$ then equilibrated at $300 \mathrm{~K}$ for 10,000 steps with an interval of $0.001 \mathrm{ps}$. The production stage was performed for 200 ps with an interval of 0.002 ps using NPT ensemble. The post-processing of the trajectory was done using the calculate interaction energy module at simulation package.

\section{Results and Discussion}

\section{FT-IR Spectroscopic Characterization}

The basic structural information of samples were obtained through FT-IR analysis and are shown in Fig. 1. The bands and peaks arise from $-\mathrm{OH}$ stretching vibration $\left(3,405 \mathrm{~cm}^{-1}\right), \mathrm{C}-\mathrm{H}$ stretching in aromatic methoxyl groups $\left(2,936 \mathrm{~cm}^{-1}\right)$, aromatic skeleton vibrations $\left(1,621 \mathrm{~cm}^{-1}\right.$ and $\left.1,519 \mathrm{~cm}^{-1}\right), \mathrm{C}-\mathrm{H}$ deformation and aromatic ring vibration $\left(1,446 \mathrm{~cm}^{-1}\right), \mathrm{C}-\mathrm{O}$ stretching in aromatic ring $\left(1,231 \mathrm{~cm}^{-1}\right.$ and $1,205 \mathrm{~cm}^{-1}$ ), and $\mathrm{C}-\mathrm{O}$ stretching of methoxyl groups $\left(1,053 \mathrm{~cm}^{-1}\right)$ to confirm that the prepared samples are polyphenols [32]. 


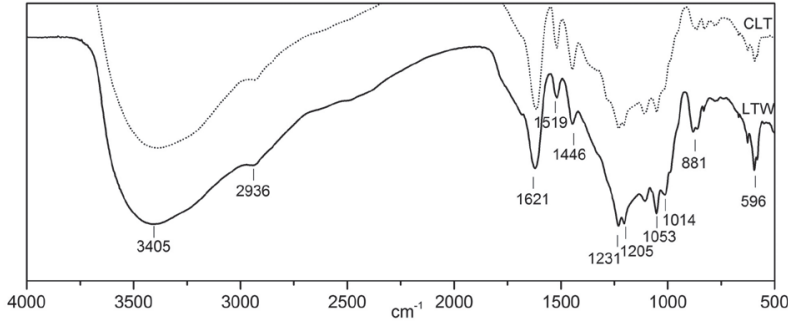

Fig. 1. FT-IR spectra of the LTW and the CLT samples.<smiles>CC1CC(c2ccccc2)Oc2ccccc21</smiles>

Fig. 2. Structure and numbering scheme of the flavon-3-ol unit.

\section{${ }^{13} \mathrm{C}$ NMR Spectra}

Detailed structural information, including the composition of subunits, average polymerization degree, and stereochemistry, can be obtained through the NMR of carbon atoms in the A ring, the $\mathrm{B}$ ring, and the pyranoid $\mathrm{C}$ ring (see Fig. 2).

Based on the NMR study of model compounds and isolated oligomers presented by Czochanska, the typical NMRs of the polyphenols are identified as follows: NMRs at 146 ppm are ascribed to the $\mathrm{C}-3^{\prime}$ and $\mathrm{C}-5^{\prime}$ in the prodelphinidin (PD) B-ring, while signals at 145 ppm represented the typical indicator for the procyanidin (PC), 70-90 ppm are sensitive to the stereochemistry of the C-ring, the C-3 in terminal units has their chemical shift around 67-68 ppm, while NMRs at $73 \mathrm{ppm}$ are attributed to the $\mathrm{C}-3$ in extension units [33].
${ }^{13} \mathrm{C}$ NMR spectra of the polyphenols in the LTW and the CLT samples are shown in Figs 3(a-b). The NMRs at $145.58 \mathrm{ppm}$ and $145.66 \mathrm{ppm}$ are found in both LTW and CLT samples. This indicates that PC is the component of the polyphenols.

Fig. 3a) has a resonance line at $68.14 \mathrm{ppm}$, which is designated to the $\mathrm{C}-3$ in the terminal unit of LTW. In the spectrum of CLT, $67.20 \mathrm{ppm}$ and $73.21 \mathrm{ppm}$ are attributed to the NMRs of terminal and extending units, respectively (Fig. 3b). Theoretically, these signals have identical $T_{1}$ and NOE values, which means the average polymerization degree could be calculated by integrating these signals [34]. Unfortunately, in the case of the spectra presented here the signal-to-noise ratio is too low for such quantification. However, the NMRs of the LTW still revealed a molecular weight lower than that of the CLT by considering the relative intensity of the C-3 NMR lines.

Resonance at 76.93 ppm, 83.48 ppm (Fig. 3a), and the 82.52 ppm, 76.06 ppm (Fig. 3b) indicated that both cis and trans stereoisomers are shown in the LTW and the CLT.

The signal assignment is performed according to the previous literature, as reported by Davis [35], and the results are summarized in Table 2.

\section{GPC Analysis}

GPC is a useful method for calculating the average molecular weight of polyphenols. Meanwhile it allows for an analysis of molecular weight distributions. The GPC column elutes the polyphenols by the size of the molecule. Consequently, the oligomers with higher molecular weights (molecular size) presented a shorter retention time, and vice versa [36].

There are obvious differences between the GPC chromatograms of the polyphenols in the LTW and the CLT samples (see Figs $4 a-b$ ). The polyphenols in the LTW are subdivided into three fractions $(\alpha, \beta$, and $\gamma)$ in accordance with the shapes of the peaks. The retention times of the fractions are: $(\alpha)$ 9.02-10.66 min, ( $\beta)$ 10.66-11.77 $\mathrm{min}$, and $(\gamma)$ 12.24-12.85 min. The polyphenols in the CLT are also subdivided into three
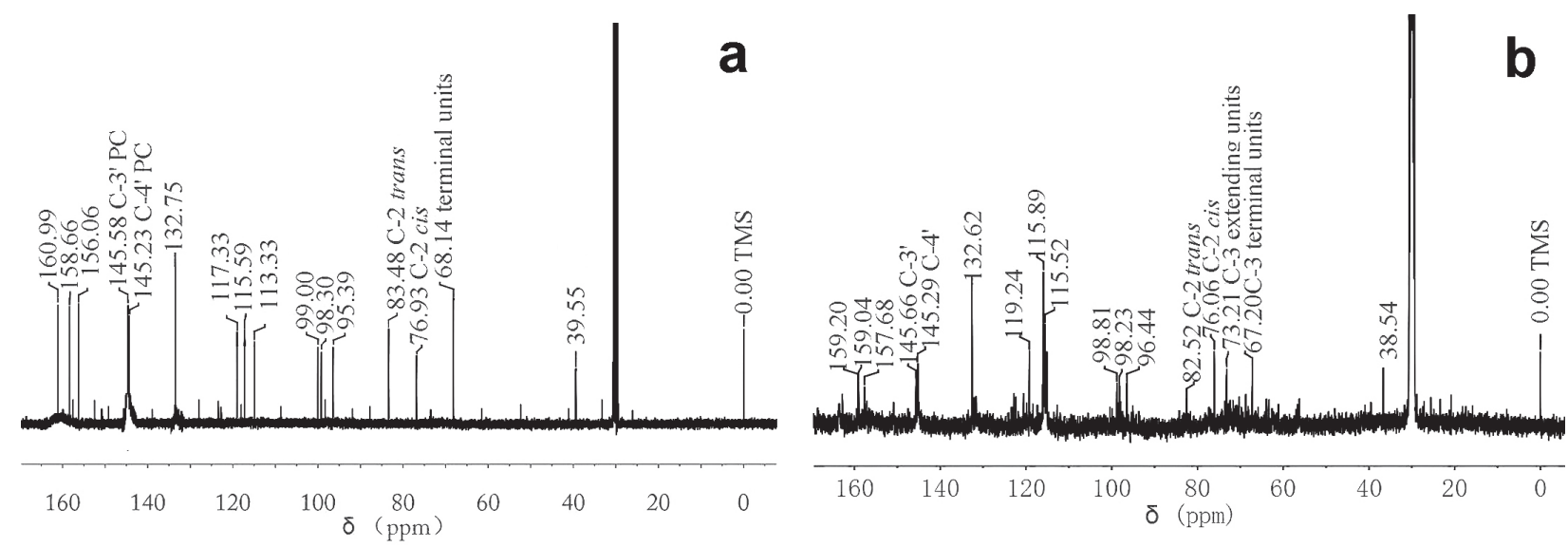

Fig. $3 .{ }^{13} \mathrm{C}$ NMR spectrum of the polyphenols in the LTW a) and the CLT b). 
Table $2 .{ }^{13} \mathrm{C}$ NMR chemical shift data for the polyphenols in the LTW and the CLT.

\begin{tabular}{|c|c|c|c|c|c|c|}
\hline & C-2(tran) & C-2(cis) & C-3(terminal) & C-3(extending) & C-4 & C-4a \\
\hline LTW & 83.48 & 76.93 & 68.14 & none & 39.55 & 99.00 \\
\hline CLT & 82.52 & 76.06 & 67.20 & 73.21 & 38.54 & 98.81 \\
\hline & C-5 & C-6 & C-7 & C-8 & C-8a & C-1' \\
\hline LTW & 158.66 & 98.30 & 160.99 & 95.39 & 156.06 & 132.75 \\
\hline CLT & 159.04 & 98.23 & 159.20 & 96.44 & 157.68 & 132.62 \\
\hline & C-2' & C-3' & C-4' & C-5' & C-6' & \\
\hline LTW & 113.33 & 145.58 & 145.23 & 115.59 & 117.33 & \\
\hline CLT & 115.52 & 145.66 & 145.29 & 115.89 & 119.24 & \\
\hline
\end{tabular}

fractions $\left(\alpha^{\prime}, \beta^{\prime}\right.$ and $\left.\gamma^{\prime}\right)$, which are referenced with the LTW chromatogram. The areas of these fractions are calculated to reveal the molecular weight distributions of the polyphenols.

The fraction with the shortest retention time in the LTW chromatogram (peak $\alpha$ ) comprises $65.8 \%$ of the total polyphenols, the corresponding fraction in the CLT (peak $\alpha^{\prime}$ ) comprises $87.5 \%$. In contrast, $5.0 \%$ of the LTW polyphenols consist of the fraction with longest retention time (peak $\gamma$ ), but the equivalent fraction (peak $\gamma^{\prime}$ ) in the CLT consists of just $2.6 \%$. The result indicates that compared with the CLT, the LTW is mainly composed of low molecular weight polyphenols. The average molecular weight $(\mathrm{Mn})$ of the polyphenols in the LTW is 1,104 Da, and the CLT also shows a higher value (3,334 Da) (Figs $4 a-b)$. The results are in agreement with the ${ }^{13} \mathrm{C}$ NMR analysis.

The subunits of the polyphenols in the LTW and the CLT are (epi)catechin (288 Da). Therefore, average polymerization degrees of the LTW and the CLT are 3.8 and 11.6, respectively, in terms of the (epi)catechin subunits. In other words, the polymerization degree of the LTW is much lower than for the CLT.

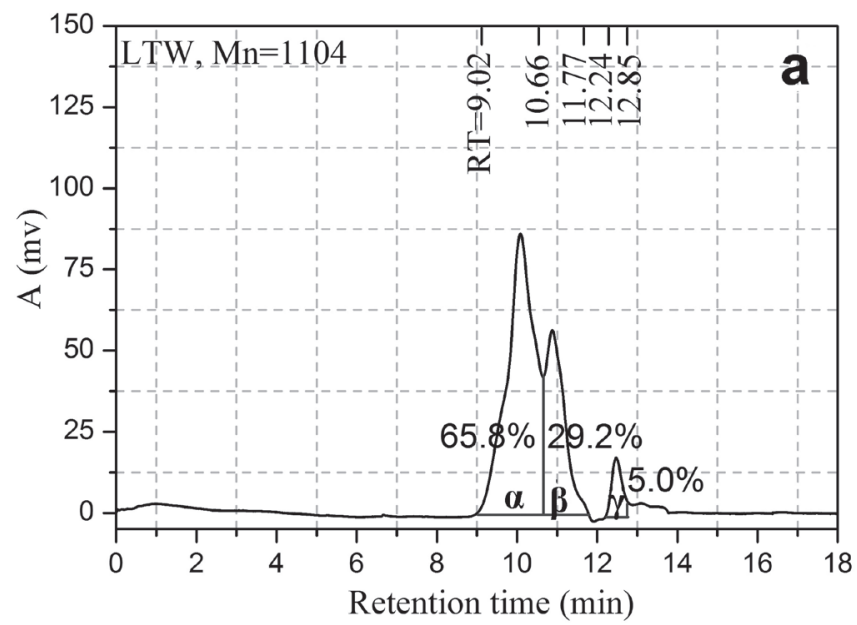

Based on the results obtained from the above analyses, the typical structure of the polyphenols in the LTW and the CLT samples are illustrated as 3-mer and 11-mer (epi) catechinins, respectively (Fig. 5).

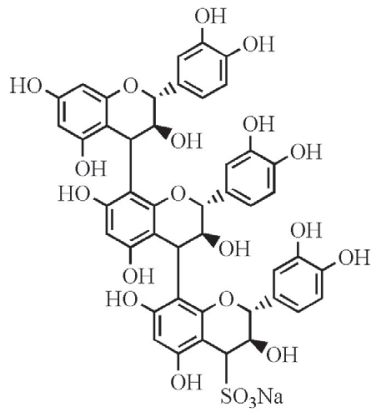

LTW

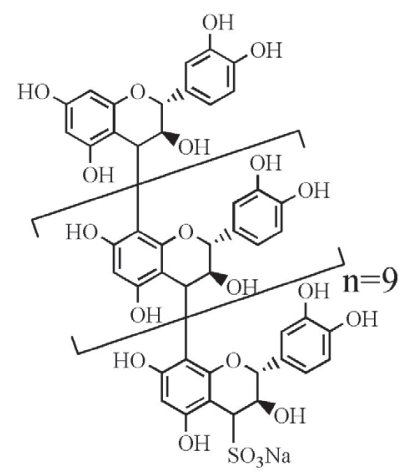

CLT
Fig. 5. Typical structures of the polyphenols in the LTW (3-mer (epi)catechin) and the CLT (11-mer (epi)catechinin) samples.

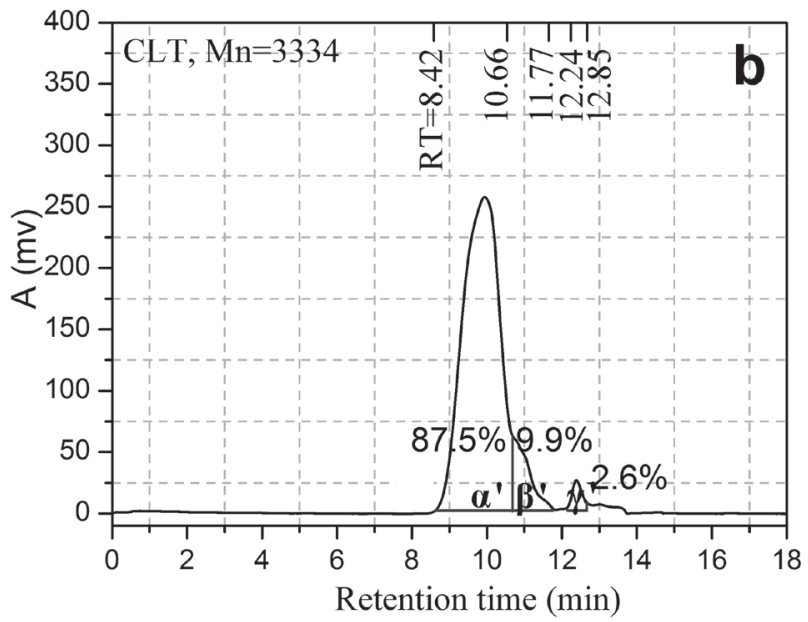

Fig. 4. GPC chromatograms of the polyphenols in the LTW a) and the CLT b). 


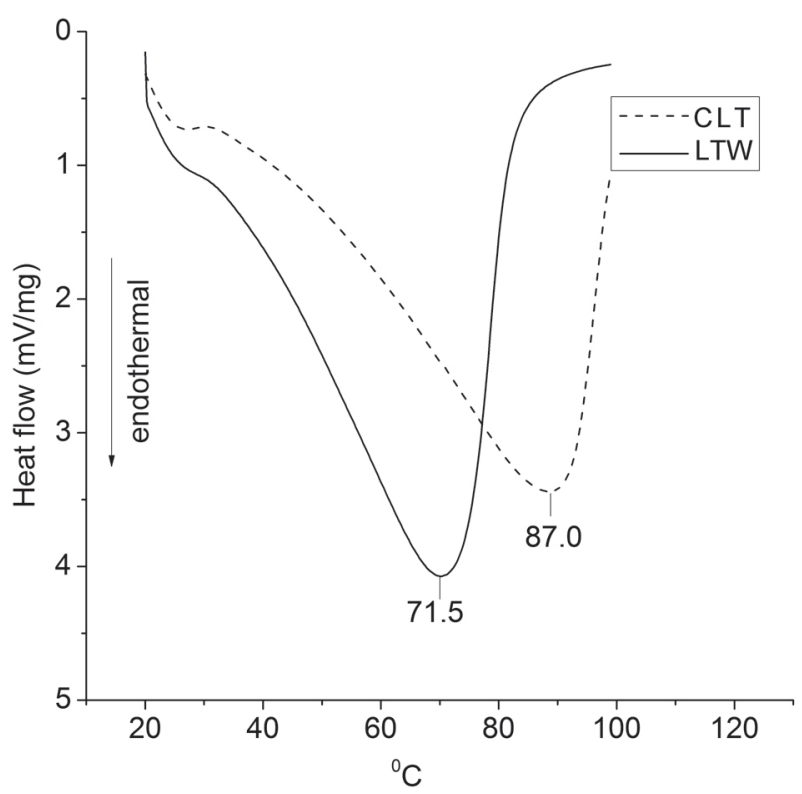

Fig. 6. DSC curve of hide powder tanned by the LTW and the CLT.

\section{Thermal Dynamic Properties of Tanned Collagen}

The thermal stability of collagen in the presence of polyphenol was assessed by DSC analysis. Fig. 6 shows the DSC thermographs of hide powder tanned with polyphenols from LTW and CLT samples. The endothermic peak is known to be associated with the transformation from triple helical to random coil of collagen, and the peak value is normally assigned to the denaturation temperature $\left(\mathrm{T}_{\mathrm{d}}\right)$ [37]. The $\mathrm{T}_{\mathrm{d}}$ of hide powder tanned by CLT is $87.0^{\circ} \mathrm{C}$; however, the hide tanned by the LTW shows a lower value $\left(71.5^{\circ} \mathrm{C}\right)$. Based on previous reports, the lower $T_{d}$ value indicates the inefficient crosslinking and incomplete reactivity of polyphenols [38]. In other words, the polyphenols in the LTW present a weaker binding ability compared with those in the CLT.

\section{Molecular Docking and Molecular Dynamic Results}

The hydrophobic-hydrophilic co-effect theory is generally accepted for illustrating the interaction between polyflavonid and protein (collagen). It can be concluded as: hydrophobic association between aromatic rings and pyrrolidine rings face containing the $\mathrm{C} \alpha$ proton, and secondary hydrogen-bonding effects help to stabilize the complex [39]. Therefore, in the present study, the binding sites are chosen and defined centrally around the areas that are rich in proline (Fig. 7a).

CDOKER Interaction energy is defined as a molecular docking score that evaluates the required energy to initiate the ligand-protein reaction: the higher absolute value it presents, the easier the binding [40]. The CDOCKER Interaction energy of the polyphenol-collagen reaction is shown in Fig. 7b). Compared with the results from CLT-collagen reaction, the required energies of the LTWcollagen reaction are obviously different. The maximum value, upper quartile, medium value, lower quartile, and minimum value, as well as the mean value of the data from LTW-collagen reaction are higher than the ones from CLTcollagen reaction. This tendency is generally presented in sites 1, 2, and 3. Therefore, compared with the CLT, the polyphenol in the LTW is inactive in the collagen-binding reaction.

The docking poses with highest CDOCKER interaction energy are shown in Fig. 8. Nine hydrogen bond are presented and eight amino acid residues (Lys9, Ser14, Hyp18, Asp21, Met21, Hyp24, Lys23, Thr24) participated in the CLT-collagen reaction. However, for the polyphenols in the LTW, only Pro23, Met24, and Hyp18 are involved in the reaction accompanied with four hydrogen bonds. Compared with the CLT-collagen complex, the number of hydrogen bond and amino acid
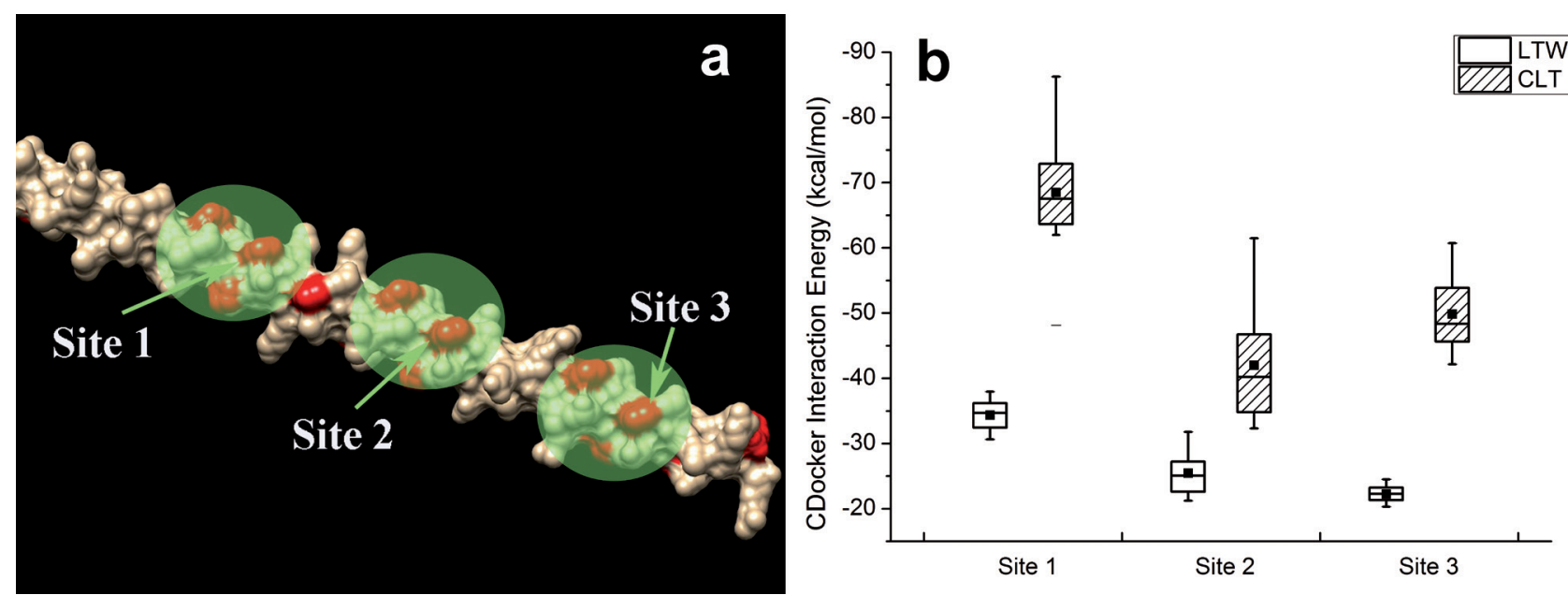

Fig. 7. The binding site a) and CDOCKER interaction energy b) of the polyphenol-collagen reactions (proline marked in red, the binding site in green). 

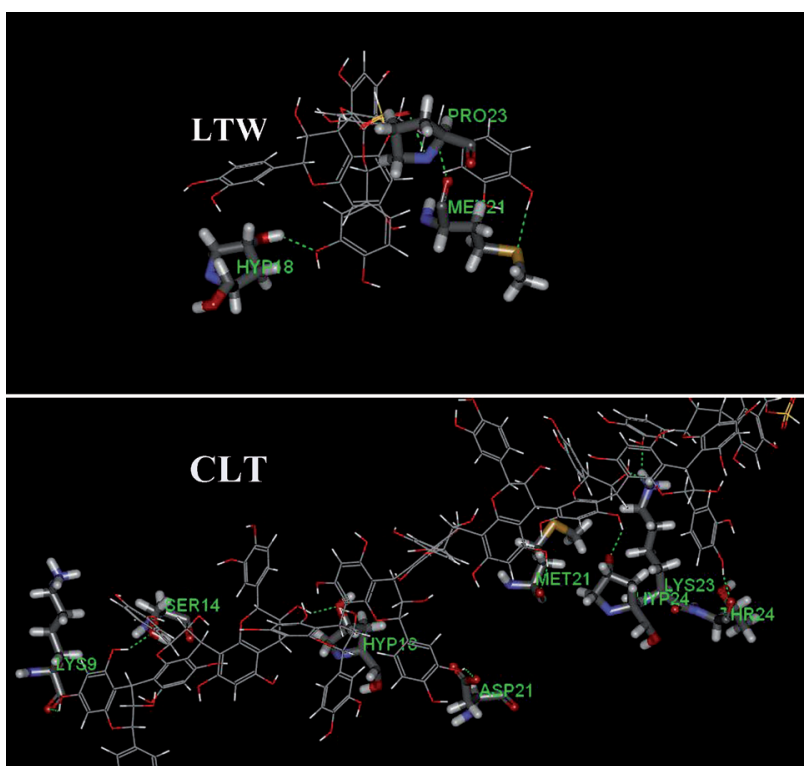

Fig. 8. Docking poses with highest CDOCKER interaction energy.

residues presents an obviously lower value in the LTWcollagen reaction.

Van Der Waals energy (a long-range force) and electrostatic energy (a short-range force) also play important roles in the protein-ligand interaction [41]. It belongs to the non-bond energy and helps to stabilize the complex, the higher absolute value shown, the more stable the complex [42]. Non-bond energy of the LTW-collagen and CLT-collagen complexes are shown in Fig. 9, in which the interaction energy is the sum of the Van Der Waals and electrostatic energies. Compared with the CLT-collagen complex, higher interaction energy is shown between the LTW and collagen molecule, including a higher Van Der Waals energy and higher electrostatic energy. Therefore, the LTW-collagen complex is less stable than the CLTcollagen complex. These results also explain the lower

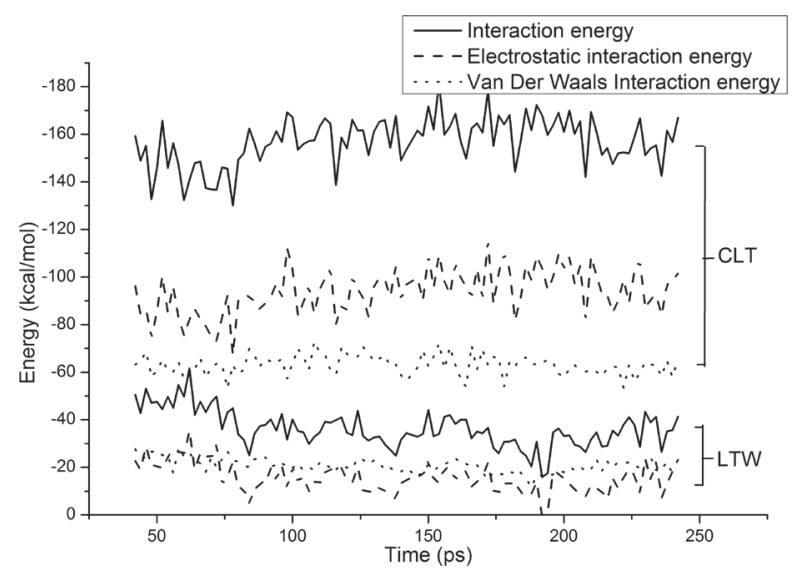

Fig. 9. Non-bond energy of LTW-collagen and CLT-collagen complexes. thermal properties of the hide powder tanned by LTW. Compared with CLT, polyphenols in the LTW are less active in the collagen-binding reaction because of their structural character. Meanwhile, less hydrogen bond and amino acids are presented in their binding process. Consequently, polyphenols with lower molecular weight remain after the vegetable tanning process.

Previous research has already reported that the polyphenols from wastewater can be recycled and reused in the leather tanning process once they are concentrated with membrane techniques $[17,43]$. However, based on the data obtained with GPC and ${ }^{13} \mathrm{C}$ NMR, the molecular weights of these polyphenols are lower than the ones in the commercial vegetable tanning agent. Actually, the related phenomenon was already discovered in the salivary protein-polyphenol reactions: the active sites of the proteins will be preferentially taken by the polyphenols, which have higher molecular weights; meanwhile, the lower molecular weight ones will be left in the solutions [44-46]. Based on the results obtained with molecular dynamic study and DSC analysis, we also discovered that the lower molecular weight character leads to a less activated molecular as well as an unstable collagen-polyphenol complex in the collagenpolyphenol reaction. Therefore, an important hint is shown for leather making: before the recycling process, if a proper chemical modification is applied in accordance with the structural differences between the polyphenols in tannin extract and tanning effluent, the binding ability of these polyphenols will be improved; meanwhile, the polyphenols in the tanning effluent will be used more efficiently.

\section{Conclusions}

The spectrum and chromatogram analyses indicate that the polyphenols in the LTW and the CLT are composed of procyanidins with both cis and trans configurations. However, the structural differences are also presented in the aspect of molecular weight and quantity of sulfonic acid group. The polymerization degree and the average molecular weight of LTW is lower than the CLT - the molecular weight of LTW was 1,104 $\mathrm{Da}$, and for the CLT the molecular weight is obviously higher at 3,334 $\mathrm{Da}$. Results from molecular modeling and DSC analysis indicate that, compared with the CLT, the polyphenols in LTW are less active in the polyphenol-collagen reaction. Furthermore, these structural differences also lead to an unstable combination for the polyphenols in LTW. Therefore, before recycling of the LTW, polyphenols should be chemically modified in accordance with these structural differences to increase the binding ability of the polyphenols. The results not only can be applied on the recycling of LTW, but also are expected to provide theory foundation for all kinds of vegetable tanning wastewater-related recycling technologies. 


\section{Acknowledgements}

The authors want to thank the Doctoral Scientific Fund Project of the Ministry of Education of China (No. 20130181130009) and the National Natural Science Foundation of China (No. 21576171) for financial support.

\section{References}

1. KOJTA A.K., GUCIA M., KRASINSKA G., SABA M., NNOROM I.C., FALANDYSZ J. Mineral Constituents of Edible Field Parasol (Macrolepiota procera) Mushrooms and the Underlying Substrate from Upland Regions of Poland: Bioconcentration Potential, Intake Benefits, and Toxicological Risk. Pol. J. Environ. Stud., 25, 2445, 2016.

2. GOSWAMI S., MAZUMDER D. Kinetic Behaviour of the Activated Sludge Process Used for Treating Composite Chrome Tannery Wastewater. Pol. J. Environ. Stud., 24, 2405, 2015

3. HACISALIHOGLU S., KARAER F. Relationships of Heavy Metals in Water and Surface Sediment with Different Chemical Fractions in Lake Uluabat, Turkey. Pol. J. Environ. Stud., 25, 1937, 2016.

4. PATI A., CHAUDHARY R., SUBRAMANI S. A review on management of chrome-tanned leather shavings: a holistic paradigm to combat the environmental issues. Environ. Sci. Pollut. R., 21, 11266, 2014.

5. RIZVI F.Z., KANWAL W., FAISAL M. Chromate-Reducing Profile of Bacterial Strains Isolated from Industrial Effluents. Pol. J. Environ. Stud., 25, 2121, 2016.

6. HUAA.K., KUSIN F.M., PRAVEENA S.M. Spatial Variation Assessment of River Water Quality Using Environmetric Techniques. Pol. J. Environ. Stud., 25, 2411, 2016.

7. MIRHOSSEINI S.M. Environmental Water Chemistry and Dissolved Radon Concentration in a Thermal Spring. Pol. J. Environ. Stud., 25, 1649, 2016.

8. WANG H., SUN L.N., LIU Z., WANG Y.G., LUO Q., CHEN S., WANG X.X., WU H. The Levels and Risks of Heavy Metals, Polycyclic Aromatic Hydrocarbons, and Polychlorinated Biphenyls in Hun River in Northeastern China. Pol. J. Environ. Stud., 25, 2167, 2016.

9. LI T.Y., YUAN X.Y., SONG Y.X., CHEN H.Y., LIU Q. HU S. Influence of Heavy Metals and Nutrient Concentrations on Selenium Geochemical Behavior in Soil-Rice System. Pol. J. Environ. Stud., 25, 185, 2016.

10. YALCIN F., KILIC S., NYAMSARI D.G., YALCIN M.G., KILIC M. Principal Component Analysis of Integrated Metal Concentrations of Bogacayi Riverbank Sediments in Turkey. Pol. J. Environ. Stud., 25, 471, 2016.

11. KHAN S.A., IBRAHIM M., JAMIL Y., AMIN N., ULLAH S., ABBAS F. Chromium quantification in a leather tanning industrial area using laser induced breakdown spectroscopy. Pol. J. Environ. Stud., 23, 2333, 2014.

12. LI W.B., MENG Z.F., LIU Z., CHEN H.Y., WU Q., XU S.E. Chromium (VI) Adsorption Characteristics of Bentonite Under Different Modification Patterns. Pol. J. Environ. Stud., 25, 1075, 2016.

13. HADIA-E-FATIMA, AHMED A. How ChromiumResistant Bacteria Can Improve Corn Growth in ChromiumContaminated Growing Medium. Pol. J. Environ. Stud., 25, 2357,2016
14. KUKLOVA M., KUKLA J., GASOVA K. Chromium and Nickel Accumulation by Plants Along an Altitudinal Gradient in Western Carpathian Secondary Spruce Stands. Pol. J. Environ. Stud., 25, 1563, 2016.

15. PARWEEN R., SHAUKAT S.S., YASMEEN K., ARA D. Evaluation of Environmental Impact on Heavy Metal Load in Cattle Milk. Pol. J. Environ. Stud., 25, 1161, 2016.

16. SUNDAR V.J., RAO J.R., MURALIDHARAN C. Cleaner chrome tanning - Emerging options. J. Clean Prod., 10, 69, 2002.

17. RAO J.R., CHANDRABABU N.K., MURALIDHARAN C., NAIR B.U., RAO P.G., RAMASAMI T. Recouping the wastewater: A way forward for cleaner leather processing. J. Clean Prod., 11, 591, 2003.

18. NACHEVA P.M., CHAVEZ G.M., HERRERA M.J. Alternative treatment strategy for tannery water reuse and material recovery. Water Sci. Technol., 50, 121, 2004.

19. CASSANO A., MOLINARI R., DRIOLI E. Saving of water and chemicals in tanning industry by membrane processes. Water Sci. Technol., 40, 443, 1999.

20. DAVIS M.H., SCROGGIE J.G. Investigation of commercial chrome-tanning systems. Part I. Separation of the complexes present by gel filtration and the effects of ageing and basification. J. Soc. Leath. Tech. Ch., 57, 13, 1973.

21. KANAGARAJ J., BABU N.K.C., MANDALA.B. Recovery and reuse of chromium from chrome tanning waste water aiming towards zero discharge of pollution. J. Clean Prod., 16, 1807, 2008.

22. SREERAM K.J., RAMASAMI T. Sustaining tanning process through conservation, recovery and better utilization of chromium. Resour. Conserv. Recy., 38, 185, 2003.

23. KANTHS.V., VENBAR., MADHANB., CHANDRABABU N.K., SADULLA S. Cleaner tanning practices for tannery pollution abatement: Role of enzymes in eco-friendly vegetable tanning. J. Clean Prod., 17, 507, 2009.

24. HE Q., YAO K., SUN D.H., SHI B. Biodegradability of tannin-containing wastewater from leather industry. Biodegradation, 18, 465, 2007.

25. LIBRALATO G., AVEZZU F., GHIRARDINI A.V. Lignin and tannin toxicity to Phaeodactylum tricornutum (Bohlin). J. Hazard Mater., 194, 435, 2011.

26. SARNI-MANCHADO P., CHEYNIER V., MOUTOUNET $M$. Interactions of grape seed tannins with salivary proteins. J. Agr. Food Chem., 47, 42, 1999.

27. ZHANG J.Z., KANG H.J., GAO Q., LI J.Z., PIZZI, A., DELMOTTE L. Performances of larch (larix gmelini) tannin modified urea-formaldehyde (TUF) resin and plywood bonded by TUF resin. J. Appl. Polym. Sci., 131, $1,2014$.

28. Society of Leather Technologists and Chemists (SLTC), LeafeMK (Ed.), IULTCS official methods of analysis. Dewsbury, United Kingdom 2001

29. GRAHAM, H.D. Stabilization of the Prussian Blue color in the determination of polyphenols. J. Agr. Food Chem., 40, 801,1992

30. LI C.M., TROMBLEY J.D., SCHMIDT M.A., HAGERMAN A.E. Preparation of an acid butanol standard from fresh apples. J. Chem. Ecol., 36, 453, 2010.

31. CHEN K.C., CHEN C.Y.C. Stroke prevention by traditional Chinese medicine? A genetic algorithm, support vector machine and molecular dynamics approach. Soft Matter, 7, 4001, 2011.

32. PING L., PIZZI A., GUO Z.D., BROSSE N. Condensed tannins from grape pomace: Characterization by FTIR and MALDI TOF and production of environment friendly wood adhesive. Ind. Crop. Prod., 40, 13, 2012. 
33. CZOCHANSKA Z., FOO L.Y., NEWMAN R.H., PORTER L.J. Polymeric proanthocyanidins. Stereochemistry, structural units, and molecular weight. J. Chem. Soc. Perk. T. 1, 10, 2278, 1980.

34. PRASAD D., JOSHI R.K., PANT G., RAWAT M.S.M., INOUE K., SHINGU T., HE Z.D. An A-type proanthocyanidin from Prunus armeniaca. J. Nat. Prod., 61, 1123, 1998.

35. DAVIS A.L., CAI Y., DAVIES A.P., LEWIS J.R. ${ }^{1} \mathrm{H}$ and ${ }^{13} \mathrm{C}$ NMR Assignments of some green tea polyphenols. Magn. Reson. Chem., 34, 887, 1996.

36. KU C.S., MUN S.P. Characterization of proanthocyanidin in hot water extract isolated from Pinus radiata bark. Wood Sci. Technol., 41, 235, 2007.

37. PIETRUCHA K. Changes in denaturation and rheological properties of collagen-hyaluronic acid scaffolds as a result of temperature dependencies. Int. J. Biol. Macromol., 36, 299, 2005.

38. HE L.R., MU C.D., SHI J., SHI J.B., ZHANG Q., SHI B., LIN W. Modification of collagen with a natural cross-linker, procyanidin. Int. J. Biol. Macromol., 48, 354, 2011.

39. MURRAY N.J., WILLIAMSON M.P., LILLEY T.H., HASLAM E. Study of the interaction between salivary proline-rich proteins and a polyphenol by ${ }^{1} \mathrm{H}-\mathrm{NMR}$ spectroscopy. Eur. J. Biochem., 219, 923, 1994.

40. KITCHEN D.B., DECORNEZ H., FURR J.R., BAJORATH J. Docking and scoring in virtual screening for drug discovery: methods and applications. Nat. Rev. Drug. Discov., 3, 935, 2004.

41. FUJINAGA M., GROS P. VANGUNSTEREN W.F. Testing the method of crystallographic refinement using molecular dynamics. J. Appl. Crystallogr., 22, 1, 1989.

42. LINS R.D., BRIGGS J.M., STRAATSMA T.P. CARLSON H.A., GREENWALD J., CHOE S.M.C., CAMMON J.A. Molecular Dynamics Studies on the HIV-1 Integrase Catalytic Domain. Biophys J., 76, 2999, 1999.

43. GERALDES V., MINHALMA M., DE PINHO M.N., ANIL A., OZGUNAY H., BITLISLI BO., SARI O. Nanofilitration of cork wastewaters and their possible use in leather industry as tanning agents. Pol. J. Environ. Stud., 18, 353, 2009.

44. SARNI-MANCHADO P., CHEYNIER V., MOUTOUNET $M$. Interactions of grape seed tannins with salivary proteins. J. Agric. Food Chem., 47, 42, 1999.

45. TENG B., JIAN X.Y., GAO Y.P., CHEN W.Y. Comparison of polyflavonoids in bayberry tanning effluent and commercial bayberry tannin: prerequisite information for vegetable tanning effluent recycling. J. Clean Prod., 112, 972, 2016.

46. CANON F., PLOYON S., MAZAURIC J.P., SARNIMANCHADO P., REFREGIERS M., GIULIANI A., CHEYNIER V. Binding site of different tannins on a human salivary proline-rich protein evidenced by dissociative photoionization tandem mass spectrometry. TETRAHEDRON, 71, 3039, 2015. 